\title{
Assessment of the contact stress distribution dependent on functional and design parameters after total hip arthroplasty
}

\author{
Emmanuel Rixrath - Sylvie Wendling-Mansuy \\ Patrick Chabrand \\ Laboratoire d'Aérodynamique et de Biomécanique du Mouvement \\ CNRS-UMSR 2164, University of Mediterranean \\ 163, avenue de Luminy, case 918 \\ F-13288 Marseille cedex 9 \\ Emmanuel.rixrath@etumel.univmed.fr
}

\begin{abstract}
A numerical model was developed to assess the contact stress distribution in total hip prosthesis as a function of geometrical parameters such as the clearance between the bearing surfaces, the inclination and thickness of the UHMWPE cup. The contact stress distribution model proposed is submitted to static loading considering the maximal force during gait and jogging. The results shows that the magnitude of the maximal contact stress remains constant for inclination values in the range of $\left[0-35^{\circ}\right]$ and increase significantly with the cup clearance and liner thickness for inclination values in the range of [35 $\left.-65^{\circ}\right]$. This model could be improved by considering other factors such as friction and dynamic loading conditions. This approach would permit to bring new perspectives for studying the long-term behaviour of total hip prostheses.

RÉSUMÉ. Le modèle numérique a été développé afin d'étudier l'influence des paramètres géométriques tels que le jeu articulaire entre les surfaces frottantes, l'inclinaison et l'épaisseur de la cupule en UHMWPE sur la répartition de la pression de contact durant un cycle de marche et de course. Les résultats montrent que la pression maximale de contact est constante pour des valeurs d'inclinaison comprises entre $\left[0-35^{\circ}\right]$ et augmente significativement avec le jeu articulaire et l'épaisseur de la cupule pour des valeurs d'inclinaison comprises entre $\left[35^{\circ}-65^{\circ}\right]$. Ce modèle pourra être amélioré en considérant d'autres facteurs tels que le frottement et des conditions dynamiques de chargement. Cette approche permettrait d'apporter de nouvelles perspectives pour étudier le comportement à long terme des prothèses totales de hanche.

KEYWORDS: contact stress, gait and jogging phases, cup inclination, clearance, thickness.

MOTS-CLÉS : pression de contact, cycle de marche et de course, inclinaison, jeu articulaire, épaisseur.
\end{abstract}

DOI:10.3166/EJCM.18.43-53 @ 2009 Lavoisier, Paris

EJCM - 18/2009. Numerical models in biomechanics, pages 43 to 53 


\section{Introduction}

The performance requirements, the expected lifetimes and the number of artificial joints implanted is increasing markedly with the increasing number of young patients requiring joint replacements, and increasing lifetime of the elderly population. The short to medium term performance of artificial joints is relatively good, but long term failure occurs often due to adverse biological reactions to the wear particles. Indeed, it appears a local periprosthetic osteolysis due to the tissue reaction on the wear particles produced by the articular friction between the couple of biomaterials. Although individual and genetic factors might also been involved, osteolysis is mainly influenced by the nature, the size and the concentration of wear debris (Maxian et al., 1996; Livermore et al., 1990).

Wear was shown to be closely related to several parameters such as (i) the geometrical designs and the mechanical properties of the acetabular components, (ii) the size of the femoral head (Livermore et al., 1990), (iii) the orientation of the acetabular component (Patil et al., 2003), and (iv) the type of contact considering sliding distance or local head roughening (Maxian et al., 1996; Brown et al., 2002). Moreover, the high stresses at the femoral head and acetabular component interface affect also the articular surface and increase wear process and debris production (Bartel et al., 1985).

Many numerical models based on finite element method have been developed to analyze the effect of the acetabular component orientation (Patil et al., 2003; D'Lima et al., 2001) or the cup thickness (Kurtz et al., 1997) on the contact stress distribution. However, the multi factorial effects (i.e. the coupling between different values of clearance, cup inclination and thickness) on stress distribution between the cup and the prosthetic head remain misunderstood. Similarly, these studies have only considered the gait phase whereas nowadays the question of the possibility of physical and sport activities like jogging arises.

The goal of the present study is to propose numerical model of total hip arthroplasty in three dimensions for analyzing the contact stress distribution dependences on the acetabular component inclination and thickness as well as on the clearance between the rigid head prosthesis and the UHMWPE cup. This analyze is done under two different static loading conditions considering the maximal force during gait and jogging phases.

\section{Method}

The total hip prosthesis is modelled as a ball-in-socket joint composed of a chrome-cobalt (CoCrMo) prosthetic head and UHMWPE cup (Figure 1). Different design parameters of the cup were reconstructed to investigate the effect of clearance and cup thickness on the contact stress distribution. The inner diameter of the cup was $28 \mathrm{~mm}$ and its outer diameter range from $40 \mathrm{~mm}$ to $52 \mathrm{~mm}$ in order to 
modelize cup thickness (d) varying from $6 \mathrm{~mm}$ to $12 \mathrm{~mm}$. The clearance between the cup and the prosthetic head is defined in the FE model as shown in Figure 2. Three different values of clearance are tested: $c=100,50,10 \mu \mathrm{m}$.

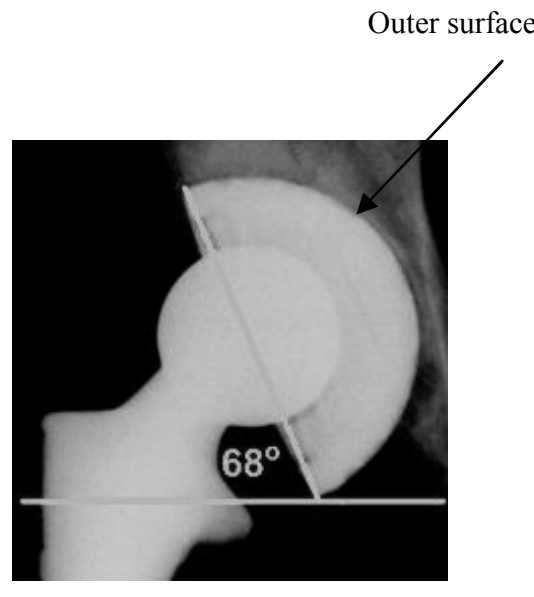

a)

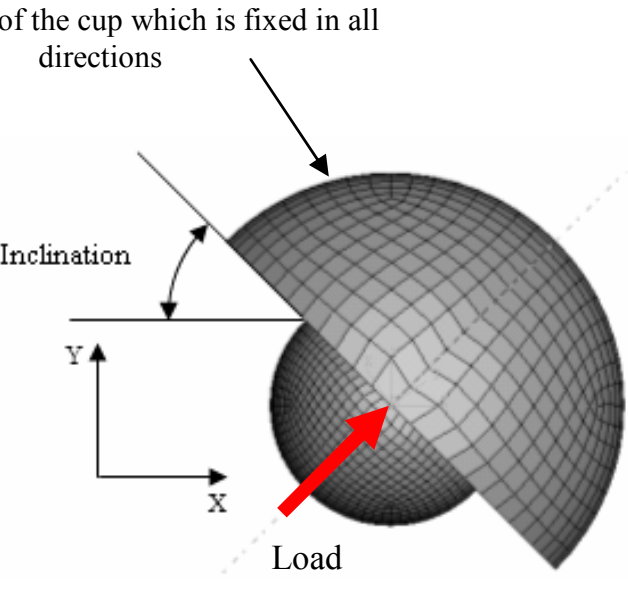

b)

Figure 1. Numerical model of the articular surfaces. a) Definition of the inclination angle. b) 3-D hexahedral mesh of the cup and prosthetic head. The load is applying to the center of the cup and it is composed of three components: $F x, F y, F z$

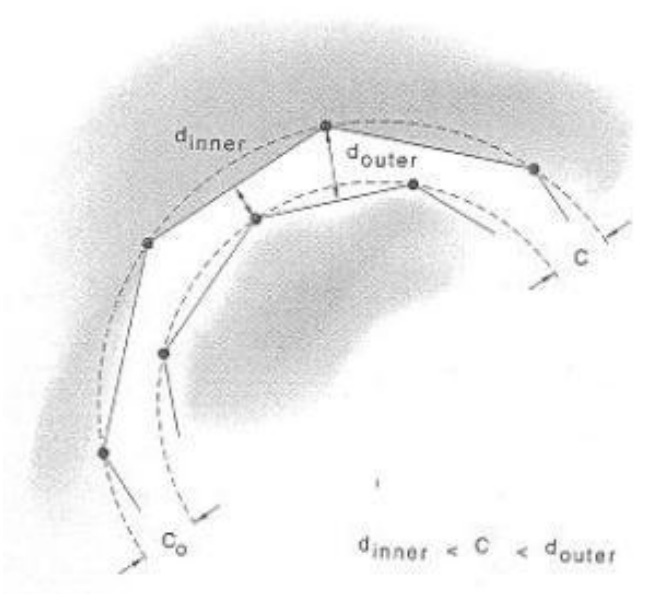

Figure 2. Initial clearance $(C)$ between the inner radius of the cup and the radius of the prosthetic head. $d_{\text {oute } r}$ is the higher distance at a node of the cup normal to a mesh segment of the head and $d_{\text {inner }}$ is the closer distance between a node of the head normal the mesh segment of the cup 
The cup is positioned in the frontal plane with a zero anteversion angle and an inclination angle which varies from $0^{\circ}$ to $75^{\circ}$ with a step of $5^{\circ}$ as show in Figure 1. The anteversion angle is obtained by the rotation around the $y$-axis.

The method adopted assumes that both articulation components are deformable bodies. The CoCrMo head was simulated by a homogeneous isotropic elastic solid and was composed of 8-nodes hexahedral elements. UHMWPE is a viscoelastic/viscoplastic material (Menges and Osswald, 1995). However, to simplify the model, the UHMWPE material was assumed to be elastic isotropic and was composed of 8-nodes hexahedral elements. The mechanical properties of both head and cup materials are shown in Table 1. No friction was assumed between the two components.

Table 1. Mechanical properties of the chrome-cobalt (CoCrMo) head and Ultra High Molecular Weight Poly-Ethylene (UHMWPE) cup

\begin{tabular}{|c|c|c|}
\hline Material & Young modulus (MPa) & Poisson coefficient \\
\hline CoCrMo & 210000 & 0.3 \\
\hline $\begin{array}{c}\text { UHMWPE } \\
\text { (Kurtz } \text { et al., 2001) }\end{array}$ & 910 & 0.45 \\
\hline
\end{tabular}

Physiological load generated during gait and jogging cycle was applied through the prosthetic head to the cup. The magnitude and direction of the resultant force was obtained from the reported in vivo measurements of hip force in a hip prosthesis (Bergmann et al., 1993, 2001). The hip load corresponds to the maximal force during a gait or jogging phase. Components of the force normalized by the body weight force $(\mathrm{Wb})$ are given in Table 2 . Boundary constraints were applied to the outer surface of the cup which is fixed in the three directions of the referential.

Table 2. Magnitude of the resultant applied force $(F)$ and its components (Fx, Fy and $\mathrm{Fz}$ ) normalized by the body weight $(\mathrm{Wb})$ during the walking and jogging phases

\begin{tabular}{|c|c|c|c|c|}
\hline & $\mathbf{F} / \mathbf{W b}$ & $\mathbf{F x} / \mathbf{W b}$ & $\mathbf{F y} / \mathbf{W b}$ & $\mathbf{F z} / \mathbf{W b}$ \\
\hline Walking & 2.33 & 0.3 & 0.31 & 2.29 \\
\hline $\begin{array}{c}\text { Jogging } \\
(8 \mathrm{Km} / \mathrm{h})\end{array}$ & 5 & 2.1 & 0.7 & 4.5 \\
\hline
\end{tabular}

The ABAQUS V6.6 (Hibbitt, Karlsson and Sorensen, Inc.) based on Newton's method to solve this nonlinear contact problem was used to analyze the contact stress distribution on the contact surface. 
The maximal contact stress is normalized by the body weight force $(\mathrm{Wb})$ as following:

$$
P^{*}=\frac{P_{\max } \cdot R^{2}}{W_{b}}
$$

with $\mathrm{R}$ the radius of the prosthetic head.

\section{Results}

The results show the distribution of the contact stress and its variations as a function of design parameters such as the cup inclination, thickness and clearance, determined under static conditions considering the peak force applied during gait and jogging phases. In that latter case, the orientation and magnitude of the applied force are different from those of the gait phase (see Table 2). Figure 3 shows that the distribution of the contact stress differs between the case of gait phase and jogging phase considering $45^{\circ}$-inclinaison of the cup and $50 \mu \mathrm{m}$-clearance, it appears in the first case (see Figure 3a) that the maximal contact stress area is smaller and located at the side of the cup than in the jogging phase (see Figure 3b). The contact stress area is larger and located more at the top of the cup. In addition, the level of magnitude of the maximal contact stress is 1.5 times higher than in the phase of gait

It appears in Figure 4 that the normalized peak contact stress $P^{*}$ is constant in the range of inclination $\left[0^{\circ}-35^{\circ}\right]$ and then increases no linearly for the 3 values of clearance tested $(\mathrm{c}=10,50,100 \mu \mathrm{m})$ in both gait and jogging phases. After $65^{\circ}$ of inclination, this increase becomes exponential because the contact stress area is highly reduced between the plastic cup at this position and the rigid artificial femoral head. In the case of gait phase, the maximal contact stress magnitude is the lowest for a $10 \mu \mathrm{m}$-clearance and becomes 2 times higher when the clearance reaches the values of $100 \mu \mathrm{m}$ (Figure $4 \mathrm{a}$ ). In the case of jogging phase, it appears that the level of magnitude of the maximal contact stress is 2 times higher than in the phase of gait for the 3 values of clearance. It can reach a value equals to 4.25 times the weight bearing stress for a clearance of $100 \mu \mathrm{m}$. The increase of the " $P *$ Inclination" curves slope is smoother and less dependent on the cup inclination.

Figure 5 shows the decrease of the normalized contact stress $P^{*}$ with the increase of the thickness of the cup whatever the value of clearance $(\mathrm{c}=10$ to $100 \mu \mathrm{m})$. In addition, the decrease slope of the $\left(P^{*}\right.$ - Thickness) curves is more important for large value of clearance $(\mathrm{c}=100 \mu \mathrm{m})$ at low values of thickness $(<9 \mathrm{~mm})$. 


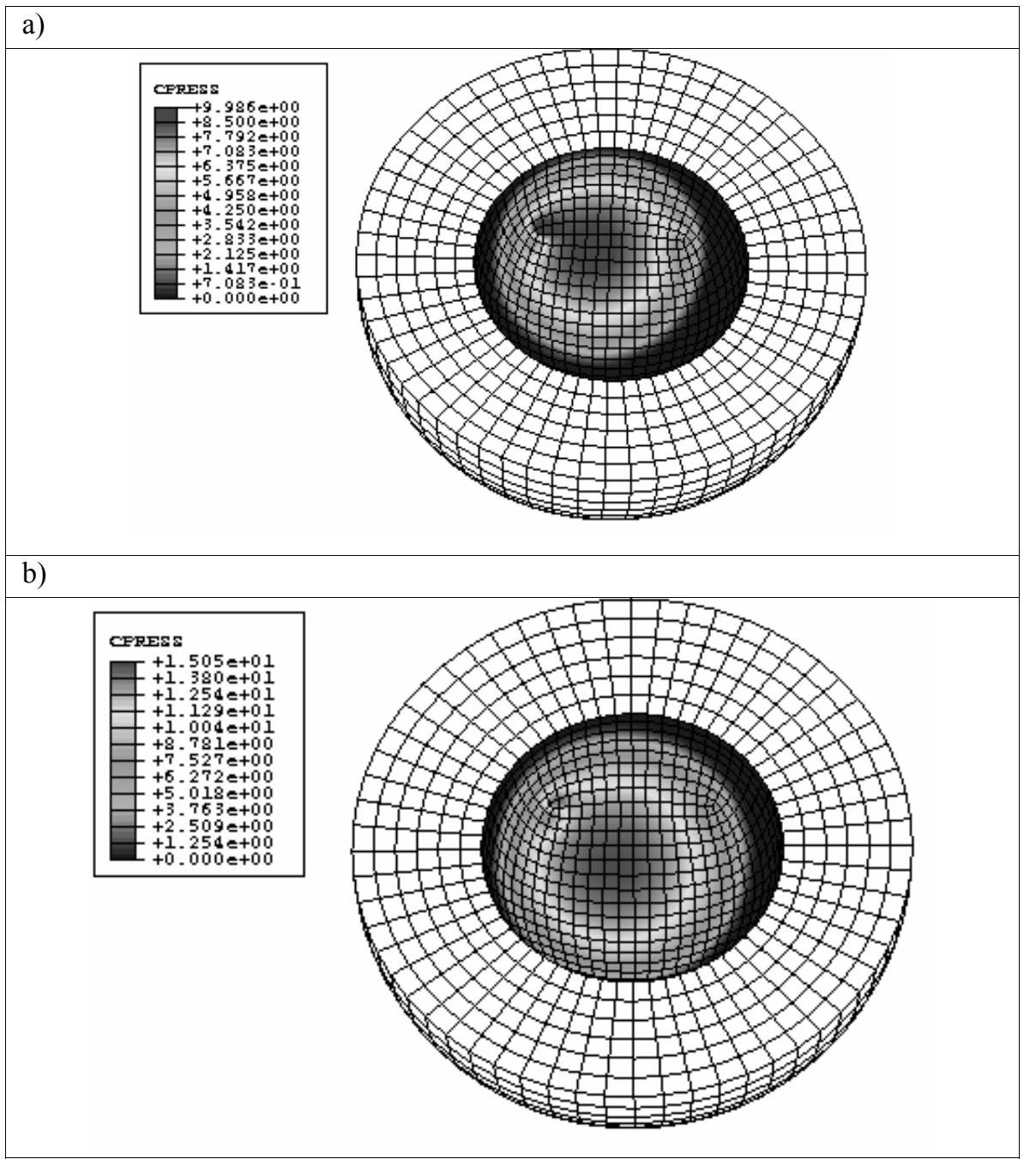

Figure 3. Contact stress distribution (in MPa) for a $45^{\circ}$ - inclination angle, a $50 \mu \mathrm{m}$ clearance and $840 \mathrm{~N}$-body weight ( $\mathrm{Wb}$ ) under maximal force during a) the gait phase and $b$ ) the jogging phase 

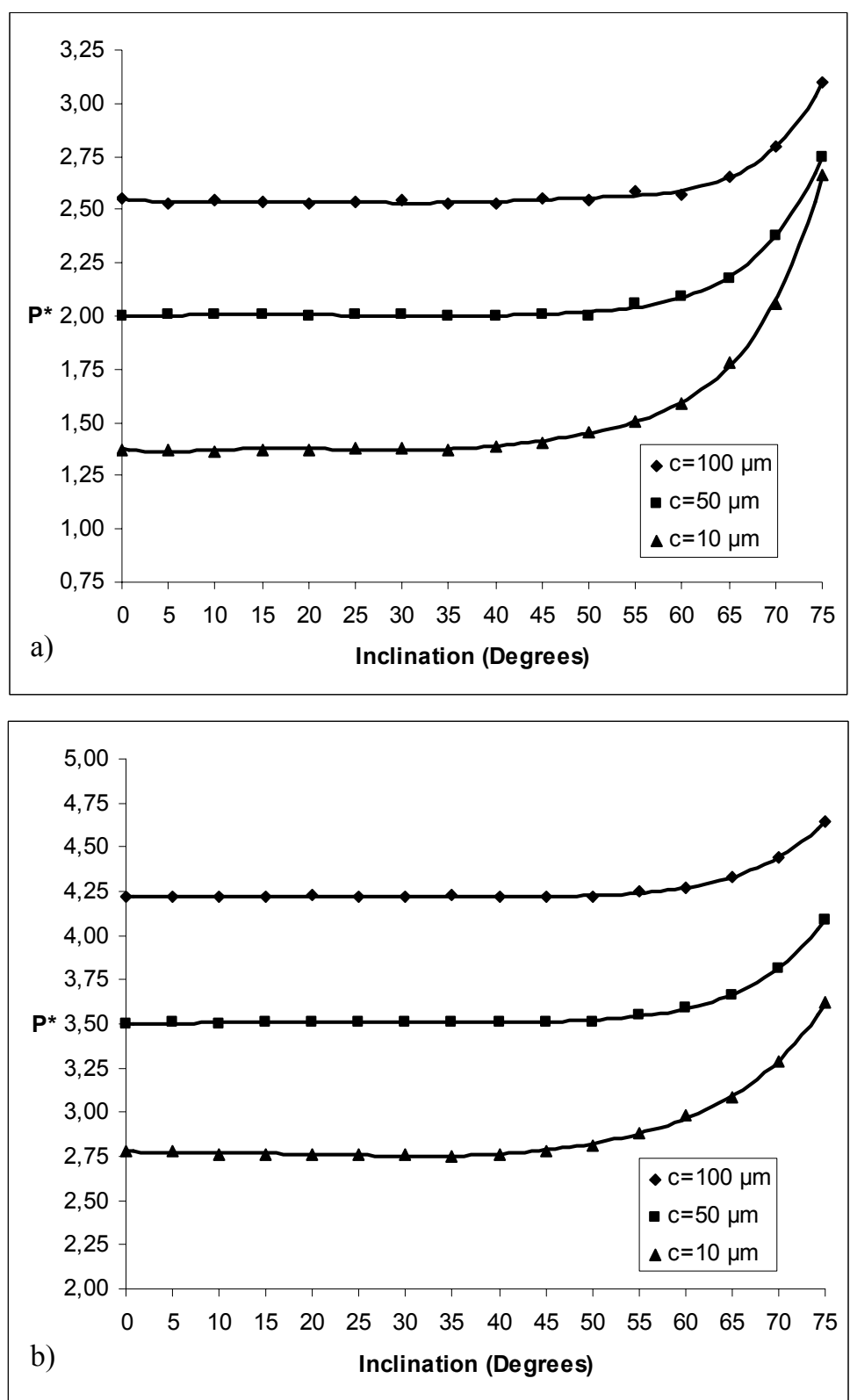

Figure 4. Normalized peak contact stress as a function of the inclination varying in the range $\left[0^{\circ}-75^{\circ}\right]$ for 3 values of clearance $(c=10,50,100 \mu \mathrm{m})$ during a) the gait phase b) the jogging phase 


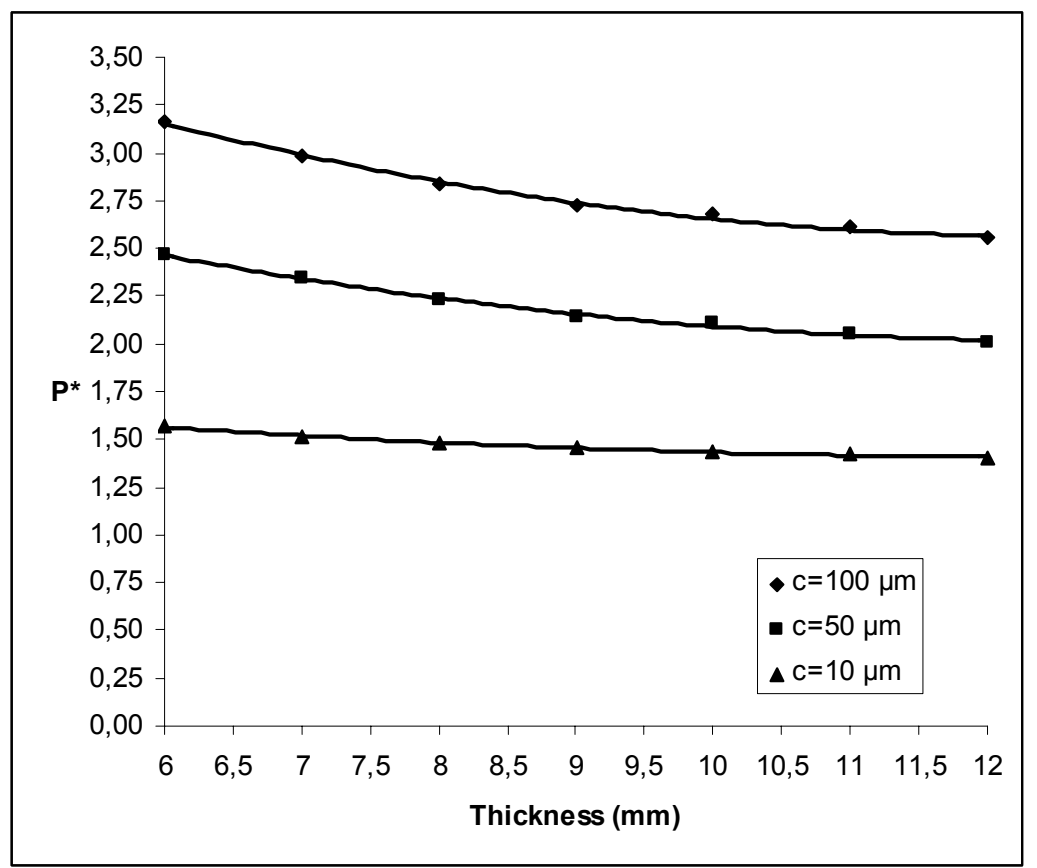

Figure 5. Normalized peak contact stress as a function of the thickness varying in the range [6mm-12mm] for 3 values of clearance $(c=10,50,100 \mu \mathrm{m})$ and for an inclination angle of $45^{\circ}$ during the gait phase

\section{Discussion}

In the present study, a 3D numerical model was developed to estimate the combined effect of design parameters as well as the loading conditions on the contact stress distribution which are crucial in wear and long term behaviour of THA. Indeed, the cup inclination during THA has been shown to influence both wear (Delschutte et al., 1998; Hirakawa et al., 2001; Patil et al., 2003) and dislocation rate (Kennedy et al., 1998).

Although the accepted cup inclination should be close to $45^{\circ}+/-5^{\circ}$ (Lewinek et al. 1978), the present results shows the significant effects of this inclination discripancies combined to the clearance between head and cup on the contact stress distribution and magnitude. It is found that the peak contact stress is substantially affected by the clearance for the acetabular cup inclination in a range of $\left[40^{\circ}-60^{\circ}\right]$ which corresponds to physiological implantation. The peak contact stress increases no linearly with the clearance and the level of inclination. While Parrate and Argenson (2007) demonstrated in recent studies on computer assisted surgery for THA, the problem to reproduce the proper inclination because of the intraoperative 
and preoperative difficulies to assess the reference plan, it appears crucial to control the acetabular position relatively to the head prosthesis position in clinical surgery.

The inclination of the cup superior to $60^{\circ}$ is not representative of real configuration due to the limits of the cup implantation. In that case, the contact stress area becomes very small and thus implies an exponential increase of the contact stress magnitude. For inclination values inferior to $40^{\circ}$, the contact stress is symmetrically distributed around the pole (i.e., direction of the peak contact stress) and is totally supported by the cup. This is why the peak contact stress remains constant in this range of inclination values whatever the level of clearance. It is to notice that once implanted the cup position varies around $45^{\circ}+/-10^{\circ}$ relatively to the longitudinal axis but can reach extreme values $\left(30^{\circ}\right.$ to $\left.60^{\circ}\right)$ in abnormal gait frequently observed within the population of elder persons.

Moreover, loading condition in the jogging phase increases the effects describe before: the level of magnitude of the contact stress is higher in the overall range of inclination tested (see Figures 2 and 3). These results show that the clearance is a crucial factor in the contact stress distribution and its increase implies an increase of the wear processes as observed in others studies (Patil et al., 2003; D'Lima et al., 2001).

Furthemore, the present results are in good agreement with those obtained by previous numerical models developed in similar conditions (static loading, body weight). For instance, Patil et al. (2003) and D'Lima et al. (2001) respectively have obtained values of contact stress of 5 to $6 \mathrm{MPa}$ (respect. 4.5 and $5.5 \mathrm{MPa}$ ) for an inclination varying in a range of $\left[35^{\circ}-55^{\circ}\right]$. In the present study, the contact stress values vary from 5.8 to $6.5 \mathrm{MPa}$ for a clearance of $10 \mu \mathrm{m}$ and from 4.9 to $5.8 \mathrm{MPa}$ for a clearance null. In addition, the decrease of the contact stress magnitude with the increase of the cup thickness was also observed by Kurtz et al. (1997) considering a fixed clearance of $50 \mu \mathrm{m}$.

The present model also showed that the clearance affects significantly this decrease, i.e., for a similar value of thickness, the maximal contact stress increased with the clearance (Figure 4). Thus, reducing the clearance between the bearing surfaces would be effective in reducing the contact stress hence preventing the onset of wear. However, a clearance inferior to $10 \mu \mathrm{m}$ between the cup and the head prosthes is quite difficult to be obtained because the engineering devices to produce the bearing surfaces are not accurate enough to realize the required tolerances.

However, the present results are oversimplified and are obtained in static conditions considering the maximal loading during gait and jogging phases with linear isotropic and elastic properties of the UHMWPE cup assuming small deformations. No friction between the cup and the artificial femoral head are assumed in the model. The contact stress $P^{*}$ would be higher considering friction. Indeed, shear stress (tangential component) is added to the normal component of the contact stress. In addition, the contact stress area obtained by the present model could be discussed comparing to the wear area observed clinically and by radiographic and tomographic data. 
To conclude, the present numerical model of the contact stress distribution permits to analyze (i) the implant-related factors such as the clearance between bearing surfaces and liner thickness of the cup, (ii) the surgery-related factors such as the inclination of the cup and (iii) the patient-related factors (i.e., physical activities - gait and jogging). This model will be easily enhanced by considering dynamic conditions and by varying other characteristic design and mechanical parameters. For instance, the model would permit to analyze alternative bearing surfaces such as cross-link PE/metal or ceramic/ceramic and metal/metal. This approach would offer to bring new perspectives for studying the long-term behaviour of total hip prostheses.

\section{Acknowledgements}

The authors thank Pr. J.N. Argenson and X. Flecher (Department of Orthopaedic Surgery, Marseille) for helpful discussion and high expertise of hip arthroplasty. This work was partly supported by grants from Altair Engineering (Antony, France) and "La Région Provence-Alpes-Côte d'Azur".

\section{References}

Bartel D.L., Burstein A.H., Toda M.D., "The effect of conformity and plastic thickness on contactujhtg stress in metal-backed plastic implants", J. Biomech. Engng, 107, 1985, p. 193-199.

Bergmann G., Graichen F., Rohlmann A., "Hip joint forces during walking and running, measured in two patients", Journal of Biomechanics, 26, 1993, p. 969-990.

Bergmann G., Graichen F., Rohlmann A., HIP 98 (2001 version), Biomechanics Lab, Benjamin franklin School of Medicine, Free University of Berlin, Germany, 2001.

Del Schutte Jr. H., Lipman A.J., Bannar S.M., Livermore J.T., Ilstrup D., Morrey B.F., "Effects of acetabular abduction on cup wear rates in total hip arthroplasty", J. Arthroplasty, 13, 1998, p. 621-626.

D'Lima D.D., Chen P.C., Colwell C.W. Jr., "Optimizing acetabular component position to minimize impingement and reduce contact stress", J. Bone Joint Surg Am., 83-A Suppl 2, 2001, Pt 2, p. 87-91.

Hirakawa K., Mitsugi N., Koshino T., "Effect of acetabular cup position and orientation in cemented total hip arthroplasty", Clin Orthop, 388, 2001, p. 135-42.

Kennedy J.G., Rogers W.B., Soffe K.E., Sullivan R.J., Griffen D.G., Sheehan L.J., "Effect of acetabular component orientation on recurrent dislocation, pelvic osteolysis, polyethylene wear, and component migration", Journal of Arthroplasty, 13, 1998, p. 530-534.

Kurtz S.M., Edidin A.A., Bartel D.L., "The role of backside pokishing, cup angle, and polyethylene thickness on the contact stresses in metal-backed acetabular components", Journal of Biomechanics, 30, 1997, p. 639-642. 
Kurtz S.M., Rimnac C.M., Bartel D.L., “A predictive model for the tensile true stress-strain behavior of chemically and mechanically degraded Ultra-High Molecular Weight Polyethylene", J Biomed Mater Res. (Appl Biomater), 350, 1998, p. 209-220.

Lewinnek G.E., Lewis J.L., Tarr R., "Dislocation after total hip replacement arthroplasties", J. Bone Joint Surg., 60A, 1978, p. 217-220.

Livermore J., Ilstrup D., Morrey B., "Effect of femoral head size on wear of the polyethylene acetabular component”, J Bone Joint Surg Am., 72, 1990, p. 518-528.

Maxian T.A., Brown T.D., Pederson D.R., Callaghan J.J., “Adaptive finite element modeling of long-term polyethylene wear in total hip arthroplasty", J. Orthop Res., 14, 1996, p. 668-675.

Menges G., Oswald T.A., Materials Science of Polymers for Engineers. Hanser Pub., Ohio, 1995.

Parratte S., Agenson J.N., "Validation and usefulness of a computer-assisted cup-positionning system in total hip arthroplasty. A prospective, randomized, controlled study", J. Bone Joint Surg Am., 89, 2007, p. 494-499.

Patil S., Bergula A., Chen P.C., Colwell C.W., D’Lima D.D., "Polyethylene wear and acetabular component orientation", J. Bone Joint Surg Am., 85-A Suppl. 4, 2003, p. 56-63. 
